\title{
$\Delta$-opioid receptor inhibition prevents remifentanil-induced post-operative hyperalgesia via regulating GluR1 trafficking and AMPA receptor function
}

\author{
AIFEN LIU ${ }^{1}$, XIAOPENG WANG ${ }^{2}$, HUI WANG ${ }^{3}$, GUOYI LV $^{1}$, YIZE LI ${ }^{4}$ and HONGMEI LI ${ }^{1}$ \\ ${ }^{1}$ Department of Anesthesiology, The Second Hospital Affiliated to Tianjin Medical University, \\ Tianjin 300042; ${ }^{2}$ Department of Anesthesiology, Shanxi Academy of Medical Science, Shanxi Dayi Hospital, \\ Taiyuan, Shanxi 030032; ${ }^{3}$ Department of General Surgery, Tianjin Public Security Hospital, Tianjin 300042; \\ ${ }^{4}$ Department of Anesthesiology, Tianjin Medical University General Hospital, Tianjin 300052, P.R. China
}

Received September 16, 2016; Accepted September 13, 2017

DOI: $10.3892 / \mathrm{etm} .2017 .5652$

\begin{abstract}
The interaction of remifentanil with glutamate systems has an important role in remifentanil-induced thermal and mechanical hyperalgesia. A previous study by our group suggested that the trafficking and function of glutamate receptor 1 (GluR1) subunits contributes to remifentanil-induced hyperalgesia by regulating the phosphorylation of GluR1 in dorsal horn neurons. The present study demonstrated that $\delta$ opioid receptor (DOR) inhibition prevented thermal and mechanical hyperalgesia, which was induced by remifentanil infusion via attenuating GluR1 subunit trafficking and $\alpha$-amino-3-hydroxy-5-methyl-4-isoxazolepropionic acid receptor (AMPAR) function in dorsal horn neurons. Sprague Dawley rats received a plantar incision and remifentanil infusion to induce a model of postoperative hyperalgesia. Thermal and mechanical pain was tested at 8 different time-points. Expression of AMPAR subunits GluR1 and DOR, as well as the phosphorylation status of GluR1 were evaluated by western blot analysis. Furthermore, the function of AMPAR in the spinal dorsal horn was measured by whole-cell patch-clamp recording. Remifentanil-induced thermal and mechanical hyperalgesia appeared after the 60-min infusions, reaching a peak level on day 2 and persisting for 5 days. Remifentanil infusion led to upregulation of membrane expression of the AMPAR subunit GluR1 and DOR ( $\mathrm{P}=0.003$ and 0.001 , respectively) no change in total GluR1 and DOR expression levels ( $\mathrm{P}=0.244$ and 0.531 , respectively). Selective DOR inhibitor naltrindole caused a reduction of remifentanil-induced
\end{abstract}

Correspondence to: Dr Hongmei Li, Department of Anesthesiology, The Second Hospital Affiliated to Tianjin Medical University, 23 Pingjiang Road, Tianjin 300042, P.R. China E-mail: lihongmei163@126.com

Key words: $\alpha$-amino-3-hydroxy-5-methyl-4-isoxazolepropionic acid receptor, glutamate receptor 1 , remifentanil, $\delta$-opioid receptor, opioid-induced hyperalgesia hyperalgesia, which was accompanied by downregulation of membrane levels of GluR1 in the spinal cord ( $\mathrm{P}=0.0013)$. In addition, DOR inhibition led to downregulation of GluR1 phosphorylated at Ser845. Furthermore, the AMPAR-mediated miniature excitatory post-synaptic current was increased in frequency and in amplitude in dorsal horn neurons $(\mathrm{P}=0.002$ and 0.0011 , respectively), which was decreased by incubation with naltrindole. Combined behavioral, western blot and electrophysiological evidence indicated that remifentanil-induced hyperalgesia was mediated by DOR activation, followed by phosphorylation-dependent GluR1 trafficking and AMPAR function enhancement in the spinal cord. DOR appears to be required for remifentanil and incision-induced hyperalgesia development and to be a potential biochemical target for treating opioid-induced postoperative hyperalgesia.

\section{Introduction}

Opioids are considered to be the most effective painkillers for acute, chronic and cancer pain in humans (1). Although opioids provide pain reduction, numerous clinical and experimental studies have demonstrated that opioid intake may increase the risk of persistent pain and pain sensitivity. This phenomenon is known as opioid-induced hyperalgesia $(\mathrm{OIH})$ and often appears after long-term opioid use (2). $\mathrm{H}$ ther mouse lymphoma cell lines 2C4 and 326T-4 were prepared in our laboratory owever, a single opioid treatment may lead to $\mathrm{OIH}$, particularly after remifentanil infusion for 60-90 min. Remifentanil is an ultra-short acting $\mu$-opioid receptor (MOR) agonist, which is widely used for the management of operative pain (3). However, remifentanil-induced hyperalgesia has a higher incidence and more rapidly leads to OIH than other opioids (4).

In the central nervous system, the excitatory transmission of glutamatergic neurons is mediated by ion flow through $\alpha$-amino-3-hydroxy-5-methyl-4-isoxazolepropionic acid receptor (AMPAR). Several studies have demonstrated that AMPAR antagonists produced an anti-hyperalgesia effect, suggesting that AMPAR has an important role in postoperative pain (5-8). AMPARs are multimeric ion channels composed of 
four subunits, glutamate receptor 1-4 (GluR1-4). It has been reported that the function of AMPARs, which is dependent on its trafficking and conduction, is determined by the composition of AMPAR subunits (9). In the dorsal horn region of the spinal cord, AMPARs principally consist of GluR1 and GluR2 subunits (10). It was reported that GluR1-containing AMPARs are permeable to $\mathrm{Ca}^{2+}$ and the that trafficking of GluR1-containing AMPAR into synapses contributes to the formation of long-term potential (11). However, GluR2-containing AMPARs have little $\mathrm{Ca}^{2+}$ permeability. Synaptic strengthening is determined by the GluR1/GluR2 ratio in dorsal horn neurons $(12,13)$. In an inflammatory pain model, the composition of AMPAR was changed, accompanied with an increased GluR1/GluR2 ratio and a greater $\mathrm{Ca}^{2+}$ permeability $(14,15)$. It has been reported that opioid exposure modified the trafficking of the GluR1 subunit but not of the GluR2 subunit in dendrites of mouse neurons (16). Phosphorylation of the Ser831 and Ser845 sites of GluR1 is essential for the function and trafficking of AMPAR (17).

The opioid receptor family modulates nociception through three G-protein coupled receptors, including MOR, $\delta$-opioid receptor (DOR) and $\kappa$-opioid receptor (KOR) (18). DORs are widely expressed in the neurons of the spinal cord dorsal horn, as well as in the dorsal root ganglia (DRG). Several studies suggested that the effects of DOR agonists are more potent than those of MOR and KOR in neuropathic pain. Peripheral nerve injury was reported to upregulate DOR expression in small and large DRG neurons (19). However, DOR protein expression was decreased in the spinal cord of a rat model of inflammatory pain (20). Furthermore, it was reported that the plasma membrane DOR was increased in response to long-term morphine, ATP or capsaicin exposure and chronic neuropathic pain (21-23). Therefore, membrane expression of DOR has an important role in DOR function and the pain process. Previous studies have indicated that DOR inhibition significantly decreased remifentanil-induced hyperalgesia via modulating membrane trafficking and N-methyl-D-aspartate receptors in the dorsal horn, indicating that naltrindole may be an anti-hyperalgesia agent for treating $\mathrm{OIH}$ (24). However, the role of DOR-AMPAR in remifentanil-induced hyperalgesia remains equivocal.

The present study assessed whether remifentanil-induced hyperalgesia was accompanied by dysregulation of DOR and AMPAR in dorsal horn neurons. It was determined whether enhancing DOR function was capable of promoting the expression of AMPAR to induce hyperalgesia in rats. It was further investigated whether DOR inhibition was able to alleviate remifentanil-induced hyperalgesia. In addition, the whole-cell patch-clamp assay was used to investigate whether the effect of remifentanil on AMPAR function is mediated by DOR.

\section{Materials and methods}

Ethics statement. All protocols and procedures adhered to the Institutional Animal Care Committee of Tianjin Medical University in line with the National Institutes of Health Guide for the Care and Use of Laboratory Animals. The protocols and procedures were approved by the Committee on the Ethics of Experiments of Tianjin Medical University (Tianjin, China; permit no. 2014-X62-27) and the Institutional Animal
Care Committee of Tianjin Medical University (Tianjin, China). All procedures were performed under sevoflurane anesthesia and considerable efforts were made to minimize animal suffering.

Animals. A total of 72 male Sprague Dawley (SD) rats (age, 8-9 weeks; weight, 250-280 g) and 24 male SD rat pups (age, 14-21 days; weight, 50-70 g), were provided by the Laboratory Animal Center of the Military Medical Sciences Academy of the Chinese PLA (Beijing, China). Rats were housed in cages with a 12-h light/dark cycle at a temperature of $22 \pm 2^{\circ} \mathrm{C}$. Rats had access to water and food ad libitum.

Intrathecal catheter placement. An intrathecal catheter implantation was performed as described by Yaksh and Rudy (25). After being anesthetized by sevoflurane inhalation (3.0\% for induction, 1.0\% for maintenance; Abbott Japan Co., Ltd., Tokyo, Japan), the rats were implanted with $8.5 \mathrm{~cm}$ polyethylene (PE-10) catheters via the atlantooccipital membrane down to the lumbar enlargement at L1-L2 of the spinal bony structure. The level of the L1-L2 spinal bony structure corresponds to the spinal cord segments of L5-S3, which are responsible for hind limb pain. The presence of the catheter in the subarachnoid space was confirmed at $24 \mathrm{~h}$ by paralysis of the hind limb. Rats exhibiting neurological deficits, including paralysis or motor function impairment were excluded from the study and euthanized immediately.

Plantar incision. The rat model of incisional pain was performed according to a previously described procedure (26). In brief, rats (weight, 250-280 g) were anesthetized with sevoflurane $(3.0 \%$ for induction, $1.0 \%$ for maintenance) via a nose mask. A 1-cm longitudinal incision was made through the skin, fascia and muscle of the right hind paw, starting $0.5 \mathrm{~cm}$ from the proximal edge. The skin was sutured with 4-0 silk sutures after the underlying flexor muscle was divided. To avoid infection, an erythromycin ointment was applied to the incision.

Drug treatments. The rats were anesthetized with sevoflurane (3.0\% for induction, $1.0 \%$ for maintenance) via a nose mask. Next, a 24-gauge over-the-needle Teflon catheter was inserted into the caudal vein and flushed with heparinized saline. The caudal vein catheter was used to infuse the experimental drugs. The control group $(\mathrm{C})$ received saline infusion $(0.1 \mathrm{ml} / \mathrm{kg} / \mathrm{min}$; $60 \mathrm{~min})$, the remifentanil group $(\mathrm{R})$ received remifentanil infusion $(1.0 \mathrm{ml} / \mathrm{kg} / \mathrm{min} ; 60 \mathrm{~min})$, the incision group (I) received a surgical incision, the remifentanil plus incision group (RI) underwent surgical incision and remifentanil infusion $(1.0 \mathrm{ml} / \mathrm{kg} / \mathrm{min} ; 60 \mathrm{~min})$, the remifentanil, incision and DOR agonist deltorphin II group (RD) received a surgical incision, remifentanil infusion $(1.0 \mu \mathrm{g} / \mathrm{kg} / \mathrm{min}$ i.v.; $60 \mathrm{~min})$ and deltorphin II (10 $\mu \mathrm{l}$ of a $4 \mathrm{nM}$ solution by intrathecal injection), and the remifentanil, incision and naltrindole group $(\mathrm{RN})$ received a surgical incision, remifentanil infusion $(1.0 \mu \mathrm{g} / \mathrm{kg} / \mathrm{min} ; 60 \mathrm{~min})$ and naltrindole $(10 \mu \mathrm{l}$ of a $30 \mathrm{nM}$ solution by intrathecal injection); $n=12$ per group.

In the patch clamp recording experiment, spinal slices from rat pups of the $\mathrm{C}$ group were incubated in artificial cerebrospinal fluid (ACSF) for $60 \mathrm{~min}$. In the R group, spinal slices 
were incubated in ACSF with $4 \mathrm{nM}$ remifentanil for $60 \mathrm{~min}$. In the RD group, spinal slices were incubated in ACSF with $4 \mathrm{nM}$ remifentanil and $4 \mathrm{nM}$ deltrophin for $60 \mathrm{~min}$. Finally, in the RN group, spinal slices were incubated in ACSF with $4 \mathrm{nM}$ remifentanil and $30 \mathrm{nM}$ naltrindole for $60 \mathrm{~min}$.

Behavioral tests. The paw withdrawal threshold (PWT) was measured using von Frey filaments (cat. no. BSEVF3; Harward Apparatus Co., Holliston, MA, USA) where the rats were placed in individual cages with a wire grid bottom. Each trial was repeated 5 times at 5-min intervals with a cut-off values of $60 \mathrm{~g}$. The paw withdrawal latency (PWL) was measured using a hot plate (cat. no. YLS-6B; Zheng Hua Biological Instrument Co., Suixi, China). Each trial was repeated 5 times at 5 -min intervals and a cut-off time of $20 \mathrm{sec}$ to avoid tissue damage.

Western blot analysis. After drug treatment, rats were sacrificed by decapitation under sevoflurane anesthesia, and the lumbar enlargement of spinal cord (L3-L5) was immediately removed and stored at $-80^{\circ} \mathrm{C}$. To prepare a total lysate, the tissue was homogenized in ice-cold lysis buffer (2\% Triton X-100, $150 \mathrm{mM} \mathrm{NaCl}, 50 \mathrm{mM}$ Tris, $100 \mathrm{~g} / \mathrm{ml}$ phenylmethylsulfonyl fluoride, $1 \mathrm{~g} / \mathrm{ml}$ aprotinin and phosphatase inhibitors; $\mathrm{pH} 7.5$ ). The lysate was centrifuged at $12,000 \mathrm{x} \mathrm{g}$ for $30 \mathrm{~min}$ at $4^{\circ} \mathrm{C}$ and the supernatant was used for a western blot analysis. To prepare membrane and cytosolic fractions, the tissue was separated into membrane, cytosolic and nuclear fractions by using a membrane, cytosolic and nuclear compartment protein extraction kit (cat. no. K3014005; Biochain Institute, Inc., Hayward, CA, USA). The protein concentration was measured using a Bio-Rad protein assay (cat. no. 5000006; Bio-Rad Laboratories, Inc., Hercules, CA, USA) and the samples were then heated to $99^{\circ} \mathrm{C}$ for $5 \mathrm{~min}$. A total of $15 \mu \mathrm{g}$ protein was loaded onto a 4-20\% Criterion ${ }^{\mathrm{TM}}$ Tris- $\mathrm{HCl}$ Protein Gel (cat. no. 3450032, Bio-Rad Laboratories, Inc.). The proteins then underwent electrophoresis and were transferred onto Immun-Blot ${ }^{\circledR}$ polyvinylidene difluoride membranes (cat. no. 1620177; Bio-Rad Laboratories, Inc.). All membranes were blocked in a buffer of 5\% non-fat milk, $50 \mathrm{mM}$ Tris- $\mathrm{HCl}$, $154 \mathrm{mM} \mathrm{NaCl}$ and $0.05 \%$ Tween-20 (pH 7.4) for $1 \mathrm{~h}$ and subsequently incubated overnight at $4^{\circ} \mathrm{C}$ with antibodies directed against GluR1, phosphorylated-GluR1 (Ser845), PKA (all 1:1,000 dilution; cat. nos. sc-7609, sc-24,593 and sc-28315, respectively. (all, Santa Cruz Biotechnology, Inc., Dallas, TX, USA), DOR (1:1,000 dilution; cat. no. ab63536; Abcam, Cambridge MA, USA) and $\beta$-actin (1:5,000 dilution; cat. no. A5316; Sigma-Aldrich; Merck KGaA, Darmstadt, Germany). The membranes were subsequently incubated with horseradish peroxidase-conjugated anti-mouse or anti-rabbit secondary antibodies (1:3,000 dilution; cat. nos. 115-035-003 and 111-035-003, respectively; Jackson Immuno Research Laboratories, Inc., West Grove, PA, USA) at room temperature for $2 \mathrm{~h}$. They were then visualized using Clarity ${ }^{\mathrm{TM}}$ Western ECL Substrate (cat. no. 170-5060; Bio-Rad Laboratories, Inc.) and exposured on the ChemiDoc XRS System with Image Lab software (Bio-Rad Laboratories, Inc.). The intensity of the blots was quantified by densitometry using Image Lab software. $\beta$-actin was used as the loading control. The western blot analysis was repeated 3 times.
Spinal cord slice preparation and whole-cell patch-clamp recording. The spinal cord slices were prepared as described previously $(27,28)$. Lumbar enlargements of 14-21 day-old rats were separated under sevoflurane anesthesia $3.0 \%$ for induction, $1.0 \%$ for maintenance). Spinal cords $\left(\mathrm{L}_{1}-\mathrm{L}_{5}\right)$ were sliced into transverse slices $(350 \mu \mathrm{m})$ with a vibratome (VT1000S; Leica Microsystems, Wetzlar, Germany). The slices were incubated in ACSF under specific conditions $\left(22-25^{\circ} \mathrm{C}, 5 \%\right.$ $\mathrm{CO}_{2}$ and $95 \% \mathrm{O}_{2}, \mathrm{pH} 7.4$ ) for $1 \mathrm{~h}$ prior to incubation. ASCF was composed of (in mM): $126 \mathrm{NaCl}, 2 \mathrm{MgCl}_{2}, 1.25 \mathrm{NaH}_{2} \mathrm{PO}_{4}$, $3.5 \mathrm{KCl}, 26 \mathrm{NaHCO}_{3}, 10 \mathrm{D}$-glucose and $2 \mathrm{CaCl}_{2}$. Whole-cell patch-clamp recordings were performed in the medial prefrontal cortex through an upright microscope (BX51W1; Olympus, Tokyo, Japan) equipped with a television monitor, which was connected to a low light sensitive charge-coupled device camera (710M; Leica Microsystems, Inc., Buffalo Grove, IL, USA). The recording pipette was produced by a vertical electrode puller (PIP5; HEKA, Lambrecht, Germany) with tip openings of 1-2 $\mu \mathrm{m}$ and a series resistance of 4-9 $\mathrm{M} \Omega$. The pipettes were filled with an intracellular solution containing (in $\mathrm{mM}$ ): $130 \mathrm{KCl}, 10$ 4-(2-hydroxyethyl) piperazine-1-ethanesulfonic acid, $0.5 \mathrm{CaCl}_{2}, 10$ ethylene-bis (oxyethylenenitrilo) tetraacetic acid, $2 \mathrm{MgCl}_{2}, 2 \mathrm{Mg}$-ATP and 0.3 Na-GTP (pH 7.3). To isolate the AMPAR-mediated miniature excitatory postsynaptic current (mEPSC), D-2-amino-5-phosphonovalerate (40 $\mu \mathrm{M})$, tetrodotoxin $(0.5 \mu \mathrm{M})$ strychnine $(2 \mu \mathrm{M})$ and bicuculline $(5 \mu \mathrm{M})$ were added to the perfusion solution. The electric signals were amplified and filtered using pCLAMP 9.2 software (Molecular Devices, Sunnyvale, CA, USA). The amplitude and frequency of AMPAR-mediated mEPSCs was analyzed using Clampfit 9.0 (Axon Instruments, Union City, CA, USA).

Statistical analysis. Statistical analysis was performed using SPSS 19.0 (IBM Corp., Armonk, NY, USA). Values are expressed as the mean \pm standard deviation. Two-way analysis of variance (ANOVA) was used for the results of the behavioral tests and one-way ANOVA was used for the western blot analysis and whole-cell patch-clamp recordings, followed by post-hoc comparisons using the Tukey-Kramer test. $\mathrm{P}<0.05$ was considered to indicate a statistically significant difference.

\section{Results}

Remifentanil and incision-induced postoperative hyperalgesia model. As in a previous study by our group (29), remifentanil treatment increased the sensitivity to heat pain and mechanical pain at the rate of $1 \mu \mathrm{g} / \mathrm{kg} / \mathrm{min}$ from 2 to $48 \mathrm{~h}$ after discontinuation of remifentanil infusion. Remifentanil alone produced higher heat pain and mechanical pain sensitivity from $2 \mathrm{~h}$ to 5 days after remifentanil infusion. As presented in Fig. 1, thermal and mechanical hyperalgesia appeared at $2 \mathrm{~h}$, reached a peak level on day 2 and persisted for 5 days after remifentanil infusion and/or incision $(\mathrm{P}<0.05)$. The results indicated that the effect of incision was about as high as that of remifentanil treatment regarding the induction of hyperalgesia, while there appears to be an enhancing effect in the RI group, which means remifentanil infusion and incision had an additive effect.

Effect of remifentanil and incision on the expression of GluRl in the spinal cord. In a previous study by our group, 


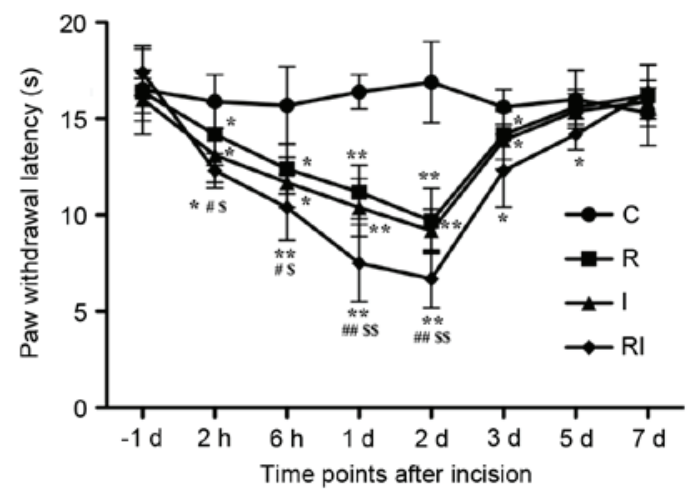

B

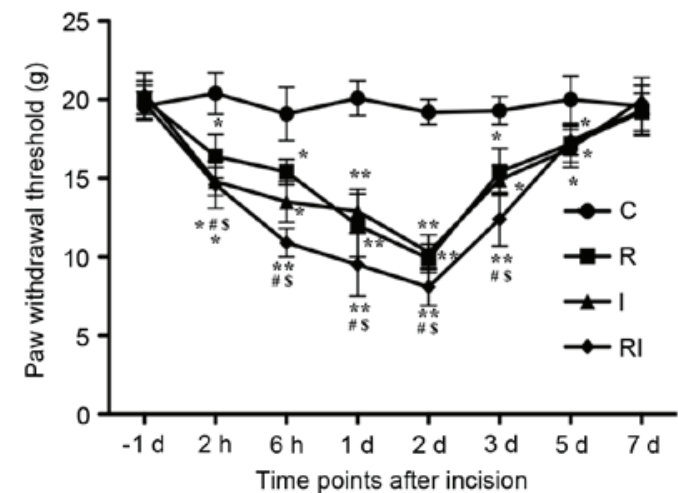

Figure 1. Remifentanil-induced post-operative mechanical and thermal hyperalgesia. (A) Paw withdrawal latency and (B) paw withdrawal threshold at one day prior to, and at 2 and $6 \mathrm{~h}$ as well as 1,2,3,5 and 7 days after infusion. Values are expressed as the mean \pm standard deviation $(\mathrm{n}=8) .{ }^{*} \mathrm{P}<0.05,{ }^{* *} \mathrm{P}<0.01$ compared with $\mathrm{C}$ group; ${ }^{\mathrm{S}} \mathrm{P}<0.05,{ }^{\mathrm{S}} \mathrm{P}<0.01$ compared with $\mathrm{R}$ group; ${ }^{\mathrm{P}} \mathrm{P}<0.05$, ${ }^{\# \#} \mathrm{P}<0.01$ compared with I group. Groups: $\mathrm{C}$, control group; $\mathrm{R}$, remifentanil group; I, incision group; RI, remifentanil plus incision group; d, day(s).

the membrane fraction of the GluR1 subunit reached a peak level on day 2 after remifentanil-induced postoperative hyperalgesia (30). Therefore, spinal cords $\left(\mathrm{L}_{1}-\mathrm{L}_{5}\right)$ were harvested at 2 days after remifentanil infusion. As presented in Fig. 2, the expression of membrane GluR1 was increased in the remifentanil group and the incision group on day 2 ( $\mathrm{P}=0.003$ and 0.004 , respectively). The membrane GluR1 in the RI group demonstrated a notable increase compared with the $\mathrm{R}$ and I groups. However, no change in the expression of total GluR1 was detected in all groups ( $\mathrm{P}>0.05$ for each). The ratio of membrane and total GluR1 was increased in the remifentanil and the incision group on day $2(\mathrm{P}=0.009$ and 0.002 , respectively). The ratio of membrane and total GluR1 in RI group demonstrated a notable increase compared with the $\mathrm{R}$ and I groups. These results suggested that remifentanil infusion or/and incision promoted GluR1 membrane trafficking in the spinal cord. Remifentanil infusion and incision had an additive effect on promoting GluR1 membrane trafficking.

Membrane insertion of DOR is increased in the spinal cord of rats with remifentanil and incision-induced hyperalgesia. Spinal cords $\left(\mathrm{L}_{1}-\mathrm{L}_{5}\right)$ were separated at 2 days after remifentanil infusion. Compared with that in the control group, the membrane fraction of DOR exhibited a significant increase after
A

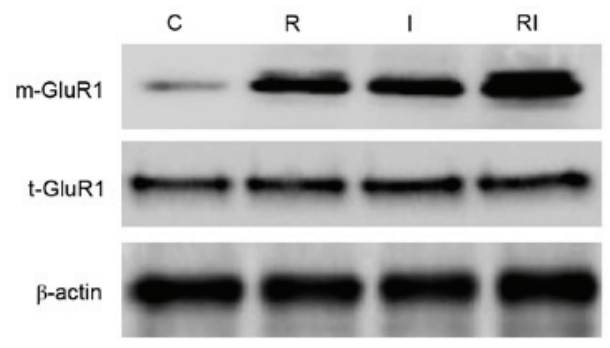

B

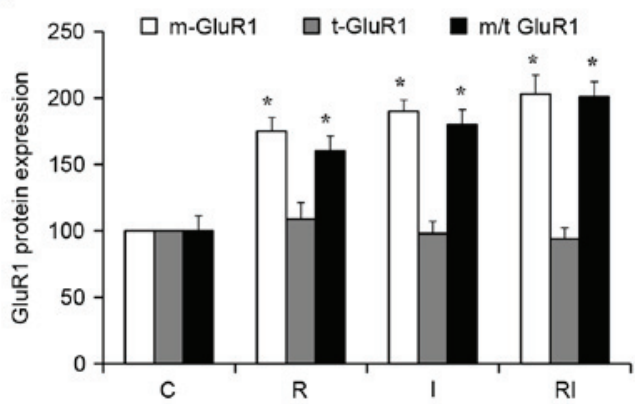

Figure 2. Effect of remifentanil and incision on the expression of GluR1 in the spinal cord. Spinal cords $\left(\mathrm{L}_{1}-\mathrm{L}_{5}\right)$ of the experimental rats were separated at 2 days after remifentanil infusion. (A) Representative western blots displaying $\mathrm{m}$-GluR1 and $\mathrm{t}$-GluR1 protein levels in the spinal cords. $\beta$-actin was used as a loading control. (B) Bar graph displaying quantified protein levels. $\mathrm{m}$-GluR1 was increased in the R, I and RI groups on day 2. Values are expressed as the mean \pm standard deviation $(n=8)$. ${ }^{*} \mathrm{P}<0.01$ compared with C group. Groups: C, control group; R, remifentanil group; I, incision group; $\mathrm{RI}$, remifentanil plus incision group. m-GluR1, glutamate receptor 1 in the membrane; t-GluR1, total GluR1.

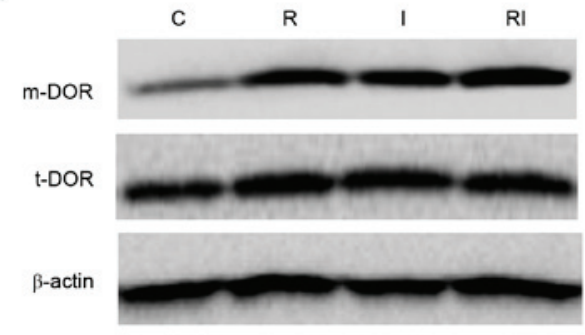

B

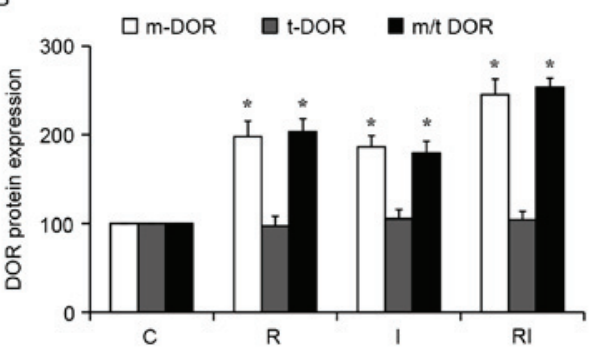

Figure 3. Activity of DOR is increased in spinal cords of rats with remifentanil-induced post-operative hyperalgesia. Spinal cords $\left(\mathrm{L}_{1}-\mathrm{L}_{5}\right)$ of the experimental rats were separated at 2 days after remifentanil infusion. (A) Representative western blots displaying $m-D O R$ and t-DOR protein levels in the spinal cords. $\beta$-actin was used as a loading control. (B) Bar graph displaying quantified protein levels. $\mathrm{m}-\mathrm{DOR}$ was increased in the R, I and RI groups on day 2, while t-DOR was not affected in any of the groups. Values are expressed as the mean \pm standard deviation $(n=8)$. ${ }^{*} \mathrm{P}<0.01$ compared with C group. Groups: C, control group; R, remifentanil group; I, incision group; RI, remifentanil plus incision group. m-DOR, $\delta$ opioid receptor in the membrane; t-DOR, total DOR. 
A

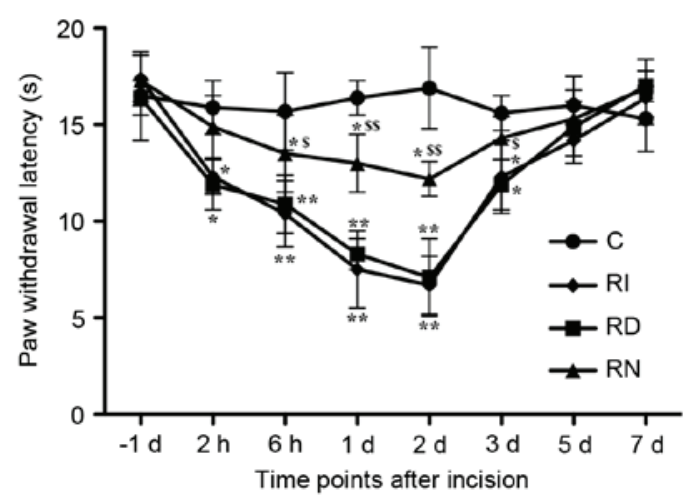

B

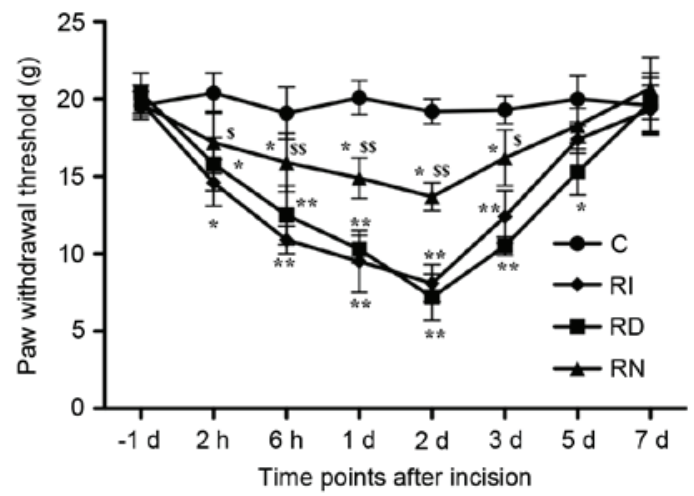

Figure 4. DOR inhibition prevents remifentanil-induced post-operative thermal and mechanical hyperalgesia. (A) Thermal PWL to noxious heat and (B) mechanical PWT were recorded one day prior to, and at 2 and $6 \mathrm{~h}$ as well as 1,2,3, 5 and 7 days after infusion. PWL and PWT had no significant difference between RI group and RN group. However, DOR antagonist naltrindole significantly attenuated the remifentanil-induced decrease in PWT and PWL. Values are expressed as the mean \pm standard deviation $(n=8)$. ${ }^{*} \mathrm{P}<0.05,{ }^{* *} \mathrm{P}<0.01$ compared with $\mathrm{C}$ group; ${ }^{\$} \mathrm{P}<0.05,{ }^{\$ \$} \mathrm{P}<0.01$ compared with RI group. Groups: C, control group; RI, remifentanil plus incision group; $\mathrm{RD}$, remifentanil, incision and DOR agonist deltorphin group; RN, remifentanil, incision and DOR antagonist naltrindole group. PWT, paw withdrawal threshold; PWL, paw withdrawal latency; DOR, $\delta$ opioid receptor.

remifentanil infusion and/or incision, whereas total protein levels of DOR were not affected $(\mathrm{P}<0.01$; Fig. 3). The ratio of membrane to total DOR increased in the remifentanil and the incision group on day $2(\mathrm{P}=0.007$ and 0.003 , respectively). The membrane DOR expression in the RI group demonstrated a notable increased compared with the $\mathrm{R}$ and I groups. The ratio of membrane to total DOR also significantly increased compared with the $\mathrm{R}$ and I groups. Together, these results suggested that remifentanil infusion and/or incision promoted DOR membrane trafficking in the spinal cord. Remifentanil infusion and incision had an additive effect on promoting DOR membrane trafficking.

DOR antagonist naltrindole attenuates remifentanil and incision-induced postoperative thermal and mechanical hyperalgesia. The selective DOR agonist deltorphin or the antagonist naltrindole were used to investigate whether DOR participates in remifentanil-induced postoperative hyperalgesia. Compared with that in the RI group, the DOR agonist deltorphin had no effect on either mechanical or thermal hyperalgesia. However, it was observed that DOR
A

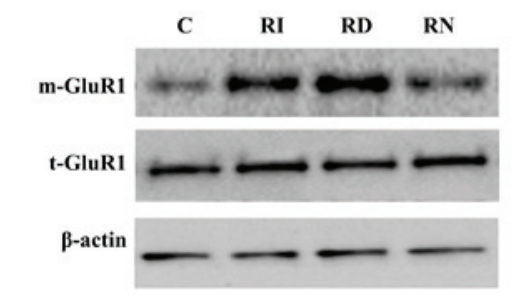

B

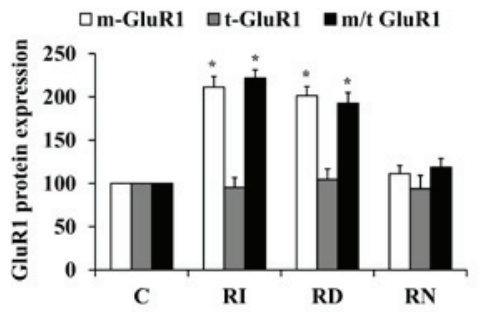

Figure 5. DOR inhibition decreases mGluR1 expression in the spines of rats with remifentanil-induced hyperalgesia. Spinal cords $\left(\mathrm{L}_{1}-\mathrm{L}_{5}\right)$ of the experimental rats were separated at 2 days after remifentanil infusion. (A) Representative western blots displaying $\mathrm{m}-\mathrm{GluR} 1$ and t-GluR1 protein levels in the spinal cords. $\beta$-actin was used as a loading control. (B) Bar graph displaying quantified protein levels. The expression levels of mGluR1 were not significantly different between the RI group and the RD group. The increased mGluR1 expression was blocked by the application of naltrindole in remifentanil- and incision-treated rats. However, no change in the levels of $\mathrm{t}$-GluR1 was detected in all groups. The increased ratio of $\mathrm{m}$ - and t-GluR1 in the RI group and RD group was restored with naltrindole treatment. Values are expressed as the mean \pm standard deviation $(\mathrm{n}=8)$. ${ }^{*} \mathrm{P}<0.01$ compared with $\mathrm{C}$ group. Groups: C, control group; RI, remifentanil plus incision group; RD, remifentanil, incision and DOR agonist deltorphin group; RN, remifentanil, incision and DOR antagonist naltrindole group. m/t-GluR, membrane/total glutamate receptor; DOR, $\delta$ opioid receptor.

antagonist naltrindole significantly decreased remifentanil-induced increases in PWT and PWL ( $\mathrm{P}<0.05$; Fig. 4). The anti-hyperalgesic effect of naltrindole was demonstrated in the rat model of remifentanil-induced postoperative hyperalgesia. These results suggested that inhibition of DOR had an anti-hyperalgesia effect in the remifentanil and incision-induced hyperalgesia model.

DOR inhibition decreases membrane insertion of GluRI in rats with remifentanil and incision-induced hyperalgesia. Compared with that in the control group, the expression of membrane GluR1 increased in dorsal horn neurons in the remifentanil and incision group $(\mathrm{P}=0.0009)$. The membrane GluR1 expression levels were not significantly different between the RI group and the RD group. Naltindole treatment inhibited remifentanil and incision-induced increases in mGluR1 and the $\mathrm{m} / \mathrm{t}$ GluR1 ratio $(\mathrm{P}=0.0013,0.0022)$. However, no change in total protein levels of GluR1 was observed in all groups ( $\mathrm{P}=0.463$; Fig. 5). The increased ratio of membrane to total DOR in the RI group and $\mathrm{RD}$ group was restored by naltrindole treatment $(\mathrm{P}=0.0065$ and 0.0035). These results suggested that DOR inhibition alleviated GluR1 membrane insertion in rats with remifentanil and incision-induced hyperalgesia.

DOR is required for remifentanil enhanced AMPAR-mediated increases in the mEPSC in dorsal horn neurons. To examine 
A

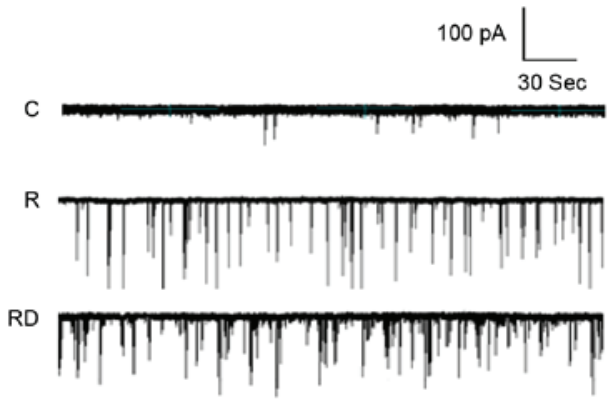

RN

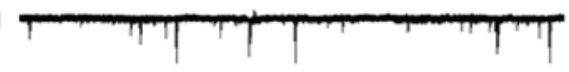

B

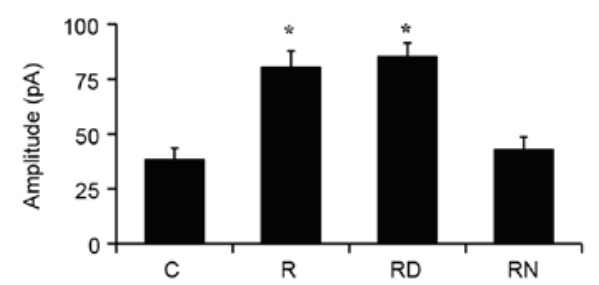

c

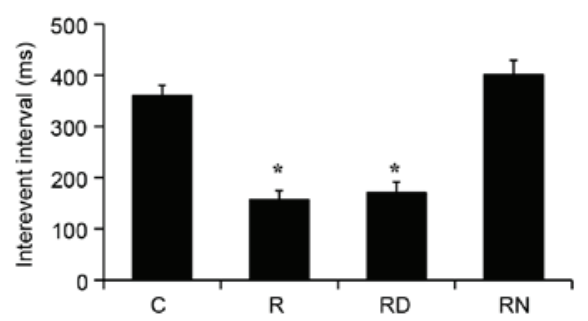

Figure 6. Naltrindole inhibits remifentanil-enhanced AMPAR-mediated enhancement of mEPSCs in dorsal horn neurons. (A) Representative traces of AMPAR mEPSCs (scale bar, 100 pA, 30 sec). (B and C) Remifentanil incubation significantly increases the amplitude of AMPAR-mediated mEPSCs while decreasing the inter-event interval of AMPAR currents. Naltrindole and remifentanil decreased changes in the amplitude and the frequency of the AMPAR current. Values are expressed as the mean \pm standard deviation $(n=8)$. "P<0.01 compared with $\mathrm{C}$ group. Groups: $\mathrm{C}$, control group; $\mathrm{R}$, remifentanil group; RD, remifentanil and DOR agonist deltorphin group; RN, remifentanil and DOR antagonist naltrindole group. AMPAR, $\alpha$-amino-3-hy droxy-5-methyl-4-isoxazolepropionic acid receptor; DOR, $\delta$ opioid receptor; mEPSC, miniature excitatory postsynaptic current.

the role of DOR in the function of AMPAR in spinal cord neurons, whole-cell patch-clamp recordings were made in the presence of remifentanil to detect the changes in the AMPAR-mediated mEPSC. Representative traces of AMPAR-mediated mEPSCs in different groups are presented in Fig. 6A. Incubation with remifentanil significantly increased the amplitude of the AMPAR-mediated mEPSC, while decreasing the inter-event interval $(\mathrm{P}=0.0012$ and 0.0004 , respectively; Fig. 6), suggesting that the function of AMPAR in the spinal cord was enhanced after treatment with $4 \mathrm{nM}$ remifentanil. No significant difference in the amplitude and frequency of the AMPAR current was observed between the remifentanil and the remifentanil + deltorphin group. However, naltrindole decreased the remifentanil-induced changes in the amplitude and the frequency of the AMPAR-mediated mEPSC when compared with that in the $\mathrm{R}$ group $(\mathrm{P}<0.001$; Fig. $6 \mathrm{~B}$ and $\mathrm{C})$. These results suggested that the increased AMPAR function in the
A

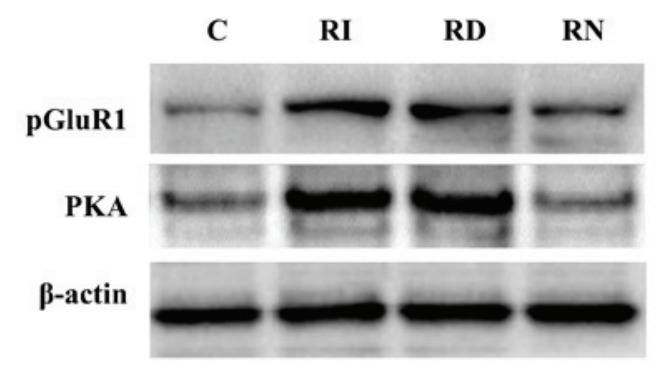

B

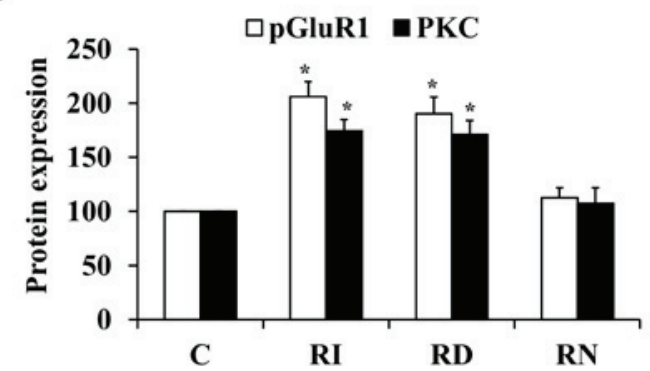

Figure 7. DOR activation significantly increases the phosphorylation of GluR1 at Ser845 and PKA in the spinal cords of rats with remifentanil-induced postoperative hyperalgesia. Spinal cords $\left(\mathrm{L}_{1}-\mathrm{L}_{5}\right)$ were separated at 2 days after remifentanil infusion. (A) The pGluR1 (Ser845) and PKA were measured by western blot analysis. $\beta$-actin was used as a loading control. (B) Quantification of the blots indicated that remifentanil infusion and incision increased the phosphorylation of GluR1 at Ser845 and PKA, and this increase was inhibited by naltrindole. Values are expressed as the mean \pm standard deviation $(n=8)$. ${ }^{*} \mathrm{P}<0.01$ compared with $\mathrm{C}$ group. Groups: C, control group; RI, remifentanil plus incision group; RD, remifentanil, incision and DOR agonist deltorphin group; RN, remifentanil, incision and DOR antagonist naltrindole group. DOR, $\delta$ opioid receptor; pGlu, glutamate receptor; PKA, protein kinase A.

remifentanil-induced hyperalgesia state is consistent with the activation of DOR in the spinal cord.

DOR inhibition significantly inhibits phosphorylation of GluR1 at Ser845 and protein kinase A (PKA) in the spinal cord of rats with remifentanil and incision-induced hyperalgesia. To further examine the role of DOR in remifentanil-induced enhancement of AMPAR expression, the phosphorylation of GluR1 at Ser845 and the expression of PKA in total protein were measured using western blot analysis. Remifentanil infusion and incision increased the phosphorylation of GluR1 at Ser 845 and the expression of PKA ( $\mathrm{P}=0.0005$ and 0.0012 , respectively). This increase was inhibited with the application of naltrindole, indicating that the phosphorylation of GluR1 and PKA was dependent on the activity of DOR in rats with remifentanil-induced hyperalgesia $(\mathrm{P}=0.0023$ and 0.0042 ; Fig. 7).

\section{Discussion}

In the present study, the thermal and mechanical hyperalgesia was increased in a rat model of remifentanil and incision-induced pain, which was partly restored through treatment with naltrindole. Furthermore, the membrane insertion of the DOR and GluR1 subunits was enhanced with the application 
of remifentanil in the spinal cord, and this was reversed by the presence of naltrindole. The whole-cell patch clamp recording results suggested that the frequency and amplitude of AMPAR-mediated mEPSCs increased in the presence of remifentanil; however, the enhanced AMPAR function was reversed by naltrindole. The present findings suggested that naltrindole inhibited the remifentanil-induced hyperalgesia effect, possibly by inducing DOR and GluR1 internalization from the synaptosomal membrane into the neuronal cytosol, thereby reducing AMPAR function in the spinal cord.

The present study demonstrated that naltrindole, a selective DOR inhibitor, reduced remifentanil-induced mechanical and thermal hyperalgesia, indicating that DOR may be involved in pain signal transmission and responses. Several studies indicated that the membrane trafficking of DOR increased in vivo and in vitro in morphine-tolerant mice, indicating that membrane insertion of DOR has an important role in opioid-induced tolerance and hyperalgesia $(31,32)$. Other studies demonstrated that the high sensitivity to opioid-induced mechanical and thermal pain was prevented with the application of naltrindole, suggesting that naltrindole may be a potential anti-hyperalgesic agent for treating $\mathrm{OIH}(24,33)$.

The subunit composition and number of synaptic AMPARs are not static. The function of AMPARs is dependent on the composition of AMPAR subunits (34). Co-expression of GluR1 and GluR3 or GluR4 is required for the formation of fully functional channels, which are $\mathrm{Ca}^{2+}$ permeable, while homomeric GluR2 channels have no function with little $\mathrm{Ca}^{2+}$ permeability (35). GluR1 subunits are the principal subunits responsible for AMPAR channel activity, and are highly expressed on the neuronal synaptic membranes in the superficial dorsal horn (36). The expression levels of GluR1 are reasonable for assessing the function of AMPAR. The present results suggested that remifentanil infusion affects the membrane trafficking of GluR1; however, there are no significant changes in GluR2 expression. Activation of $\mathrm{Ca}^{2+}$-permeable AMPARs in dorsal horn neurons enhances AMPAR-mediated synaptic transmission (30). The results of the present study supported the involvement of GluR1 trafficking in spinal sensitization and pain behavior. In dorsal horn neurons, application of DOR inhibitor naltrindole apparently inhibited the accumulation of GluR1 in the plasma membrane fraction. This indicated that remifentanil-induced hyperalgesia promoted synaptic delivery of GluR1-containing AMPARs in a DOR-dependent manner.

A previous study reported that the GluR1 subunit in dorsal horn neurons was phosphorylated at the Ser845 residue following neuropathic pain. The phosphorylation of Ser845 in GluR1 by PKA regulates the open channel probability of AMPARs (37). The membrane insertion of GluR1 depends on the phosphorylation of GluR1 at Ser845 by PKA $(38,39)$. A previous study reported that phosphorylation of GluR1 at Ser845 was increased in inflammatory pain, which was mediated by the activation of PKA $(40,41)$. In the present study, it was demonstrated that DOR increased the phosphorylation of the GluR1 subunit of AMPARs at Ser845 alongside increases of PKA expression in rats with remifentanil-induced hyperalgesia.

The present study indicated that inhibition of DOR abolished the hypersensitivity to thermal and mechanical pain during remifentanil-induced postoperative hyperalgesia development and maintenance. DOR activation increased the expression of AMPAR subunit GluR1 and the function of AMPARs by altering pGluR1 levels in the spinal cord. Although the mechanism of OIH remains to be fully elucidated, DOR appears to be a novel target for preventing and treating remifentanil and incision-induced hyperalgesia.

\section{Acknowledgements}

The present study was supported by research grants from the Science and Technology Foundation of Tianjin Public Security Bureau (grant no. 2011KYSGAY021), the National Natural Science Foundation (grant no. 81400908) and the Young Scholar Research Grant of Chinese Anesthesiologist Association (grant no. 2015).

\section{References}

1. Lee HJ and Yeomans DC: Opioid induced hyperalgesia in anesthetic settings. Korean J Anesthesiol 67: 299-304, 2014.

2. Célèrier E, Laulin JP, Corcuff JB, Le Moal M and Simonnet G: Progressive enhancement of delayed hyperalgesia induced by repeated heroin administration: A sensitization process. J Neurosci 21: 4074-4080, 2001

3. Derrode N, Lebrun F, Levron JC, Chauvin M and Debaene B: Influence of peroperative opioid on postoperative pain after major abdominal surgery: Sufentanil TCI versus remifentanil TCI. Br J Anaesth 91: 842-849, 2003.

4. Koppert W and Schmelz M: The impact of opioid-induced hyperalgesia for postoperative pain. Best Pract Res Clin Anaesthesiol 21: 65-83, 2007.

5. Dickenson AH, Chapman V and Green GM: The pharmacology of excitatory and inhibitory amino acid-mediated events in the transmission and modulation of pain in the spinal cord. Gen Pharmacol 28: 633-638, 1997.

6. Garry EM and Fleetwood-Walker SM: A new view on how AMPA receptors and their interacting proteins mediate neuropathic pain. Pain 109: 210-213, 2004.

7. Shypshyna MS and Veselovsky NS: Presynaptic $\mathrm{Ca}^{2+}$-permeable AMPA-receptors modulate paired-pulse depression in nociceptive sensory synapses. Neurosci Lett 585: 1-5, 2015.

8. Yoshimura $\mathrm{M}$ and Nishi S: Excitatory amino acid receptors involved in primary afferent-evoked polysynaptic EPSPs of substantia gelatinosa neurons in the adult rat spinal cord slice. Neurosci Lett 143: 131-134, 1992.

9. Furuyama T, Kiyama H, Sato K, Park HT, Maeno H, Takagi H and Tohyama M: Region-specific expression of subunits of ionotropic glutamate receptors (AMPA-type, KA-type and NMDA receptors) in the rat spinal cord with special reference to nociception. Brain Res Mol Brain Res 18: 141-151, 1993.

10. Engelman HS, Allen TB and MacDermott AB: The distribution of neurons expressing calcium-permeable AMPA receptors in the superficial laminae of the spinal cord dorsal horn. J Neurosci 19: 2081-2089, 1999.

11. Citri A and Malenka RC: Synaptic plasticity: Multiple forms, functions and mechanisms. Neuropsychopharmacology 33: 18-41, 2008.

12. Burnashev N, Monyer H, Seeburg PH and Sakmann B: Divalent ion permeability of AMPA receptor channels is dominated by the edited form of a single subunit. Neuron 8 : 189-198, 1992.

13. Sommer B, Keinänen K, Verdoorn TA, Wisden W, Burnashev N, Herb A, Köhler M, Takagi T, Sakmann B and Seeburg PH: Flip and flop: A cell-specific functional switch in glutamate-operated channels of the CNS. Science 249: $1580-1585,1990$.

14. Hartmann B, Ahmadi S, Heppenstall PA, Lewin GR, Schott C, Borchardt T, Seeburg PH, Zeilhofer HU, Sprengel R and Kuner R: The AMPA receptor subunits GluR-A and GluR-B reciprocally modulate spinal synaptic plasticity and inflammatory pain. Neuron 44: 637-650, 2004. 
15. Kopach O, Kao SC, Petralia RS, Belan P, Tao YX and Voitenko N: Inflammation alters trafficking of extrasynaptic AMPA receptors in tonically firing lamina II neurons of the rat spinal dorsal horn. Pain 152: 912-923, 2011.

16. Beckerman MA, Ogorodnik E and Glass MJ: Acute morphine associated alterations in the subcellular location of the AMPA-GluR1 receptor subunit in dendrites of neurons in the mouse centra nucleus of the amygdala: Comparisons and contrasts with other glutamate receptor subunits. Synapse 67: 692-704, 2013.

17. Hu XD, Huang Q, Yang X and Xia H: Differential regulation of AMPA receptor trafficking by neurabin-targeted synaptic protein phosphatase-1 in synaptic transmission and long-term depression in hippocampus. J Neurosci 27: 4674-4686, 2007.

18. Allouche S, Noble F and Marie N: Opioid receptor desensitization: Mechanisms and its link to tolerance. Front Pharmacol 5 : 280, 2014.

19. Bushlin I, Gupta A, Stockton SD Jr, Miller LK and Devi LA: Dimerization with cannabinoid receptors allosterically modulates delta opioid receptor activity during neuropathic pain. PLoS One 7: e49789, 2012.

20. Stone LS, Vulchanova L, Riedl MS, Williams FG, Wilcox GL and Elde R: Effects of peripheral nerve injury on delta opioid receptor (DOR) immunoreactivity in the rat spinal cord. Neurosci Lett 361: 208-211, 2004.

21. Bao L, Jin SX, Zhang C, Wang LH, Xu ZZ, Zhang FX, Wang LC, Ning FS, Cai HJ, Guan JS, et al: Activation of delta opioid receptors induces receptor insertion and neuropeptide secretion. Neuron 37: 121-133, 2003.

22. Wang HB, Zhao B, Zhong YQ, Li KC, Li ZY, Wang Q, Lu YJ, Zhang ZN, He SQ, Zheng HC, et al: Coexpression of delta- and mu-opioid receptors in nociceptive sensory neurons. Proc Nat Acad Sci USA 107: 13117-13122, 2010.

23. Zhang X, Bao L and Guan JS: Role of delivery and trafficking of delta-opioid peptide receptors in opioid analgesia and tolerance. Trends Pharmacol Sci 27: 324-329, 2006.

24. Zhao M and Joo DT: Enhancement of spinal N-methyl-D-aspartate receptor function by remifentanil action at delta-opioid receptors as a mechanism for acute opioid-induced hyperalgesia or tolerance. Anesthesiology 109: 308-317, 2008

25. Yaksh TL and Rudy TA: Chronic catheterization of the spinal subarachnoid space. Physiol Behav 17: 1031-1036, 1976.

26. Pogatzki EM, Niemeier JS, Sorkin LS and Brennan TJ: Spinal glutamate receptor antagonists differentiate primary and secondary mechanical hyperalgesia caused by incision. Pain 105 97-107, 2003.

27. Tian Y, Yang Z and Zhang T: Zinc ion as modulator effects on excitability and synaptic transmission in hippocampal CA1 neurons in Wistar rats. Neurosci Res 68: 167-175, 2010.

28. Yang K, Takeuchi K, Wei F, Dubner R and Ren K: Activation of group I mGlu receptors contributes to facilitation of NMDA receptor membrane current in spinal dorsal horn neurons after hind paw inflammation in rats. Eur J Pharmacol 670: 509-518, 2011.
29. Li Y, Wang H, Xie K, Wang C, Yang Z, Yu Y and Wang G: Inhibition of glycogen synthase kinase-3 $\beta$ prevents remifentanil-induced hyperalgesia via regulating the expression and function of spinal N-methyl-D-aspartate receptors in vivo and vitro. PLoS One 8: e77790, 2013.

30. Li YZ, Tang XH, Wang CY, Hu N, Xie KL, Wang HY, Yu YH and Wang GL: Glycogen synthase kinase- $3 \beta$ inhibition prevents remifentanil-induced postoperative hyperalgesia via regulating the expression and function of AMPA receptors. Anesth Analg 119: 978-987, 2014

31. Cahill CM, Morinville A, Lee MC, Vincent JP, Collier B and Beaudet A:Prolonged morphinetreatment targets delta opioid receptors to neuronal plasma membranes and enhances delta-mediated antinociception. J Neurosci 21: 7598-7607, 2001.

32. Gendron L, Lucido AL, Mennicken F, O'Donnell D, Vincent JP, Stroh T and Beaudet A: Morphine and pain-related stimuli enhance cell surface availability of somatic delta-opioid receptorsin rat dorsal root ganglia. J Neurosci 26: 953-962, 2006.

33. Wang C, Li Y, Wang H, Xie K, Shu R, Zhang L, Hu N, Yu Y and Wang G: Inhibition of DOR prevents remifentanil induced postoperative hyperalgesia through regulating the trafficking and function of spinal NMDA receptors in vivo and in vitro. Brain Res Bull 110: 30-39, 2015.

34. Malinow R and Malenka RC: AMPA receptor trafficking and synaptic plasticity. Annu Rev Neurosci 25: 103-126, 2002.

35. Hollmann $\mathrm{M}$ and Heinemann S: Cloned glutamate receptors. Annu Rev Neurosci 17: 31-108, 1994.

36. Kerr RC, Maxwell DJ and Todd AJ: GluR1 and GluR2/3 subunits of the AMPA-type glutamate receptor are associated with particular types of neurone in laminae I-III of the spinal dorsal horn of the rat. Eur J Neurosci 10: 324-333, 1998.

37. Banke TG, Bowie D, Lee H, Huganir RL, Schousboe A and Traynelis SF: Control of GluR1 AMPA receptor function by cAMP-dependent protein kinase. J Neurosci 20: 89-102, 2000.

38. Barry MF and Ziff EB: Receptor trafficking and the plasticity of excitatory synapses. Curr Opin Neurobiol 12: 279-286, 2002.

39. Esteban JA, Shi SH, Wilson C, Nuriya M, Huganir RL and Malinow R: PKA phosphorylation of AMPA receptor subunits controls synaptic trafficking underlying plasticity. Nat Neurosci 6: 136-143, 2003.

40. Fang L, Wu J, Lin Q and Willis WD: Protein kinases regulate the phosphorylation of the GluR1 subunit of AMPA receptors of spinal cord in rats following noxious stimulation. Brain Res Mol Brain Res 118: 160-165, 2003.

41. Fang L, Wu J, Zhang X, Lin Q and Willis WD: Increased phosphorylation of the GluR1 subunit of spinal cord alpha-ami no-3-hydroxy-5-methyl-4-isoxazole propionate receptor in rats following intradermal injection of capsaicin. Neuroscience 122: 237-245, 2003. 